\title{
Low temperature hydrothermal growth of aligned zinc oxide nanowires using FTO substrate
}

\author{
[M. Quddamah, Tanveer Ashraf, Tahir Zaidi, Zahid Ali, Mansoor Hussain]
}

\begin{abstract}
Zinc oxide nanowires have been mostly observed due to special material properties and showing special performance in photonic, electronics and optics. Aligned Zinc oxide nanowires were grown on FTO substrate by using the hydrothermal process. This growth technique is bottom up, low cost and easy. The seed layer is deposited onto the substrate by spin coating with low temperature and nanowires are affected by the thickness of seed layer. Afterwards, the nanowires were growing hydrothermally onto those seed layers. Different characterizations have been done in detail using X-ray Diffraction (XRD), Scanning electron microscopy (SEM), Raman spectroscopy and photoluminescence spectroscopy (PL). The SEM is used to relives the presence of nanowire with hexagonal shape in vertical direction. The XRD measurements show diffraction pattern of wurtzite structure.
\end{abstract}

Keywords-ZnO, FTO, nanowires, hydrothermal growth

\section{Introduction}

The $\mathrm{ZnO}$ has a wide band gap semiconductor due to which it become best candidate among different wide band gap materials for large scale and economic optoelectronics applications $[1,2]$. $\mathrm{ZnO}$ has high radiation resistance, high break down fields, large situation rate, effective luminescence and so that's why it has utilized for high power devices at high frequency and high temperature [3]. Zinc oxide has various advantages over remaining compound semiconductors in manufacturing costs which are less as compare for $\mathrm{GaN}$. Zinc oxide has a large exciton binding energy range up to $60 \mathrm{mev}$ which is much greater than $\mathrm{ZnSe}(26 \mathrm{mev})$ and $\mathrm{GaN}(25 \mathrm{mev})$, this make them stable for Ultra Violet emitter at the room temperature and also a best candidate for fabrication of blue and UV LEDs [4]. Zinc oxide nanowires (NWs) have one-dimensional (1D) structure showing quantum confinement effect and also having a greater surface to volume ratios. $\mathrm{ZnO}$ has a n-type semiconductor material and have difficult task for p-type doping. $\mathrm{ZnO}$ has a wurtzite crystalline structure. Zinc oxide has synthesized to nanowire by different methods such as vapor-liquid-solide growth [5, 6], chemical vapour deposition [7-9], pulse laser ablation techniques [10], and hydrothermal method. On different temperature $\mathrm{ZnO}$ nanowires has been synthesized, as vapor phase process done on high temperature and

Muhammad Quddamah Khokhar National University of Sciences and Technology, Pakistan

\section{Tahir Zaidi}

National University of Sciences and Technology, Pakistan

Mansoor Hussain

National University of Sciences

and Technology, Pakistan solution phase require low temperature. Initially the $\mathrm{ZnO}$ nanowires were synthesized by vapor phase owing high vacuum and high temperatures $\left(450\right.$ to $\left.900^{\circ} \mathrm{C}\right)$ [11]. But it limit the integration of flexible electronic devices and large size of substrate. Other popular method for synthesis of $\mathrm{ZnO}$ nanowires is vapor liquid solid growth, settling high quality nanowire using sapphire as a substrate [12]. ZnO nanowires also grow by pulse laser deposition method. Usually high quality of $\mathrm{ZnO}$ nanowires produce by the gas phase, however the commercial potential is restrict by the high temperature round about $500^{\circ} \mathrm{C}$, for allied array sapphire substrate is use and also high cost of deposition. Only two important approaches for low temperature methods remain for growth is hydrothermal method and electrochemical method [13]. Low temperature growth is promising candidate for commercialization due their large scale production, their simplicity, high quality products and low cost. Some advantages of hydrothermal process over the remaining method is that its low temperature $\left(90^{\circ} \mathrm{C}\right)$ growth, work at atmospheric pressure, cover lager area of substrate about 4inch diameter, easy to control and environmental friendly. Smooth and uniform growth of $\mathrm{ZnO}$ nanowire array with high aspect ratio is synthesized by low temperature hydrothermal method. Their amazing performance in photonics, optics and electronics $\mathrm{ZnO}$ NWs become much appealing candidates for multiple uses such as light-emitting diodes [14], gas sensors [15], UV lasers [16], solar cells [17], photo-detectors [18], resistive switching [19] and photo-catalysts [20].

\section{Experimental}

\section{A. ZnO seed solution preparation}

By using sol-gel spin coating method a uniform and homogenous zinc oxide nanoparticles were deposited. Before the deposition of seed layer, solution was put together by utilizing zinc acetate dehydrate $\left[\mathrm{Zn}\left(\mathrm{CH}_{3} \mathrm{COO}\right)_{2}\right.$. $\left.2 \mathrm{H}_{2} \mathrm{O}\right]$ as a precursor and Ethanol $(\mathrm{EtOH})$ use as a solvent. Zinc oxide solution was obtained by mixing the solvent with zinc acetate dehydrate. To confirm the zinc power was fully mixed in the ethanol, the mixture was stirring constantly for $1 \mathrm{~h}$ without heating. Before deposition the solution was stored in room temperature for $24 \mathrm{~h}$.

\section{B. ZnO seed layer preparation}

NILOP, Pakistan

A FTO coated glass template was used as a substrate. Before the seed layer coating on substrate, the substrate was passed through a standard cleaning process. It was cleaned in ultrasonic bath with acetone, poly ethylene glycol and ethanol and then rinsed with deionized water (DIW). In last, the substrate was dried with optical tissue. A spin coater was used for deposition of zinc oxide solution on sterilized substrates at 3,000 rpm for $30 \mathrm{~s}$. After coating, the substrate 
Proc. of the Sixth International Conference on Advances in Computing, Electronics and Communication - ACEC 2017. Copyright (C) Institute of Research Engineers and Doctors. All rights reserved.

ISBN: 978-1-63248-138-2 doi: 10.15224/ 978-1-63248-138-2-04

was dried on hot plate for round about at $100^{\circ} \mathrm{C}$ for 5 minutes. The process of deposition was repeated four times to get more homogenous and thicker $\mathrm{ZnO}$ films. To remove the solvent and organic components from films, the annealing process was done. Conventional furnace was used for annealing purpose. Figure 1 shows the preparation process of zinc oxide thin film.

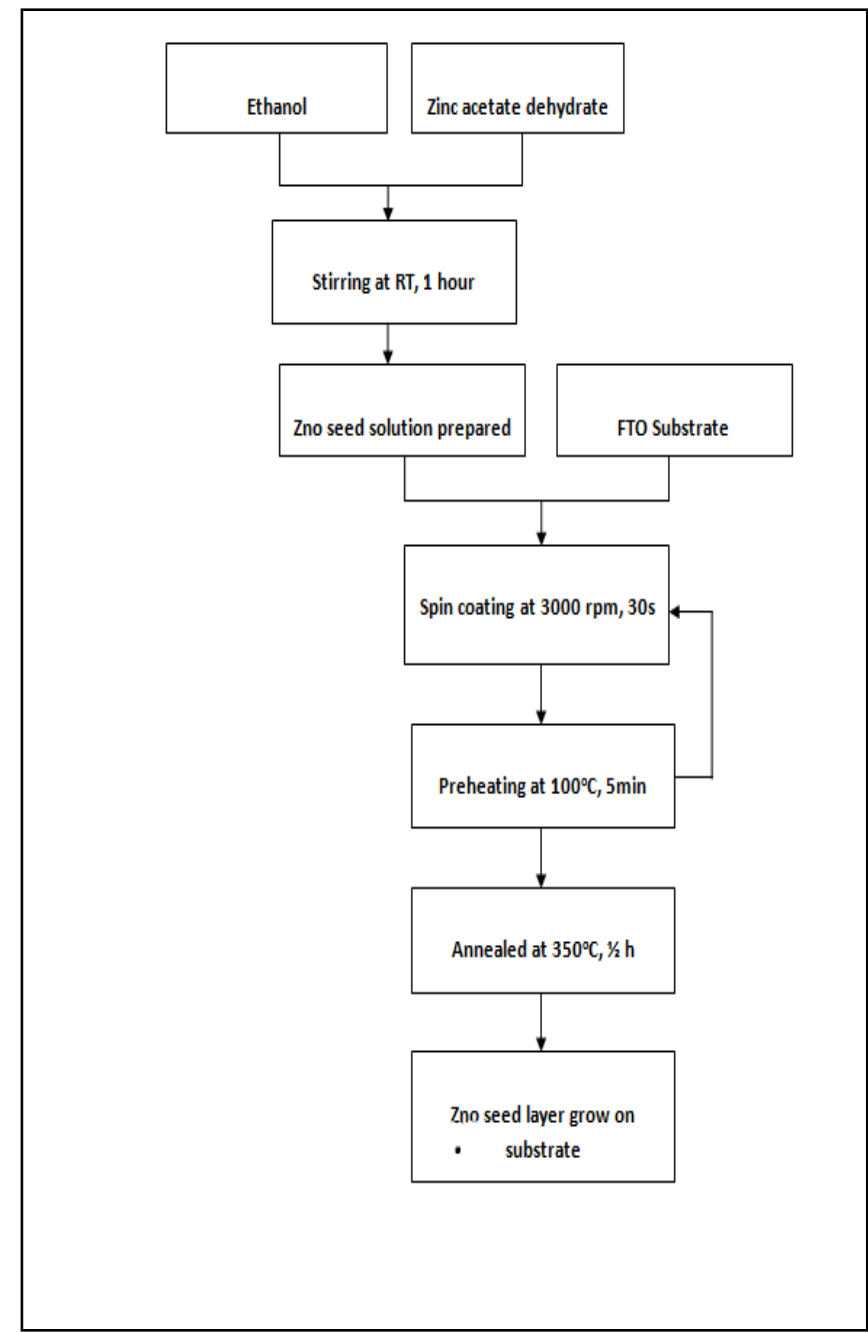

Figure 1: $\mathrm{ZnO}$ thin film preparation process flow.

\section{ZnO NWs formation}

Zinc oxide nanowires were obtained from the uniform coated $\mathrm{ZnO}$ nanoparticles on substrate by hydrothermal growth. The homogenous solution consisted of hexamethylenetetramine (HMT) and zinc nitrate hexahydrate. The complete dissolution of HMT powder and $\mathrm{Zn}\left(\mathrm{NO}_{3}\right)_{2}$ in DIW was done with the help of stirrer for 15 minutes at room temperature. The nanowires were grown by dipping the substrate that was settled upside down in above solution. The growth procedure was done in laboratory oven by heating the solution at $90^{\circ} \mathrm{C}$ for $3 \mathrm{~h}$. After the growth of nanowires, sample washed with tape water and then rinsed with DIW for elimination of salts from sample surface. Last step, the sample placed in oven for heat-treated for $1 / 2 \mathrm{~h}$ at $300^{\circ} \mathrm{C}$. The growth procedure of zinc oxide nanowires is shown in figure 2.

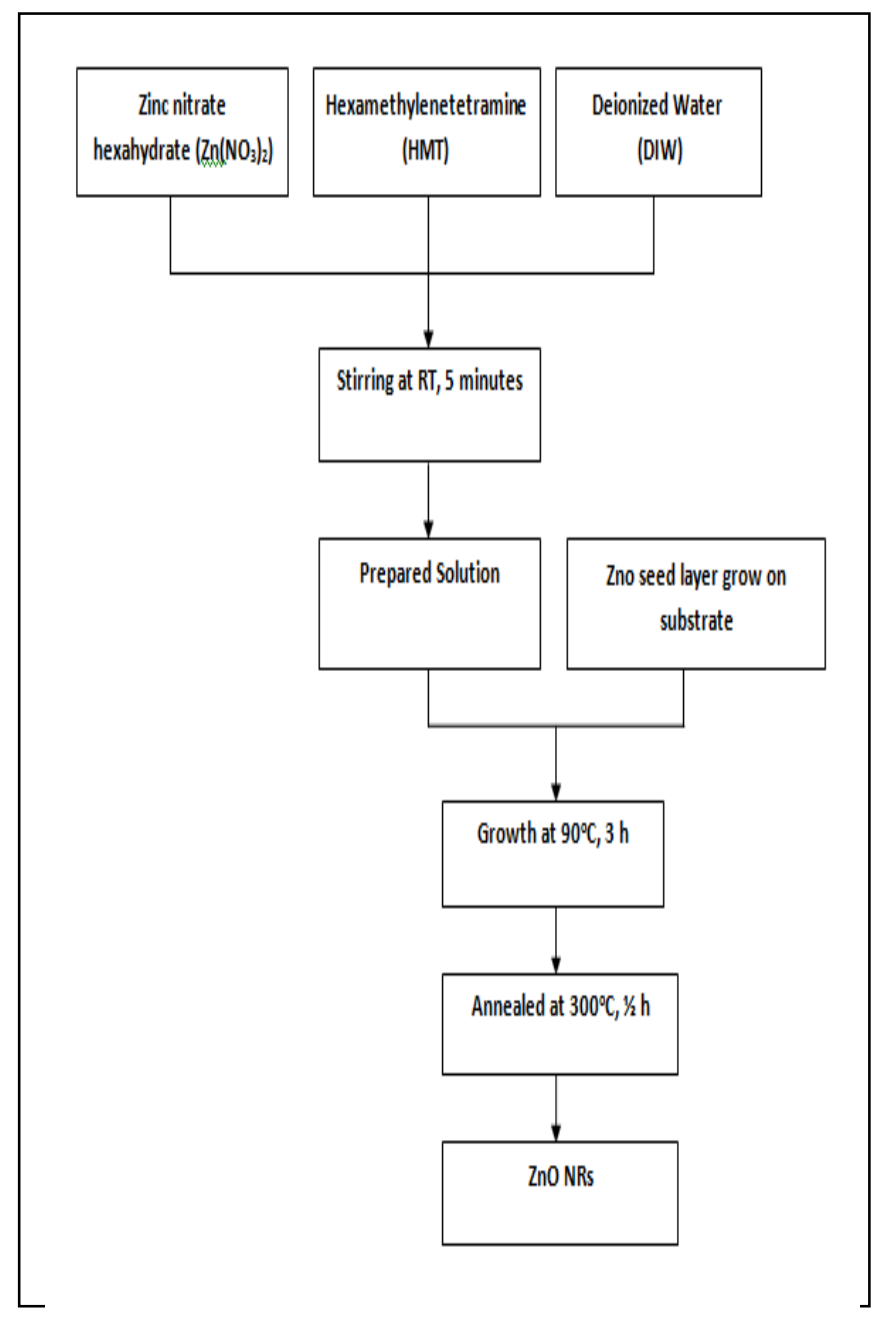

Figure 2: $\mathrm{ZnO}$ nanowires growth process.

\section{Material Characterization}

By using scanning electron microscopy surface morphology of zinc oxide nanowires was analyzed. Crystal properties and crystallization was study by X-ray diffraction. Through photoluminescence the luminescence and optical properties of zinc oxide nanowire were studied. In addition, Raman provides a fingerprint of molecule by which it can be identified.

\section{Result and discussion}

\section{A. SEM Characterization}

Figure 3(a), (b) show the top and cross-sectional view of zinc oxide nanowires by using SEM that was synthesized by using ethanol as a solvent. Hexagonal morphology was showed by all the synthesized zinc oxide nanowires. Entire substrate was covered by nanowires, and an aliened nanowire was mostly grown. The diameter of zinc oxide nanowires was obtained approximately 200nm. Mostly nanowires showed largest diameter which synthesized by ethanol as a solvent. The diameter of nanowires is strongly influenced on the grain size of zinc oxide seed layer. As the grain size increased, the diameters of nanowires were also increase. 
Proc. of the Sixth International Conference on Advances in Computing, Electronics and Communication - ACEC 2017. Copyright (C) Institute of Research Engineers and Doctors. All rights reserved.

ISBN: 978-1-63248-138-2 doi: 10.15224/ 978-1-63248-138-2-04
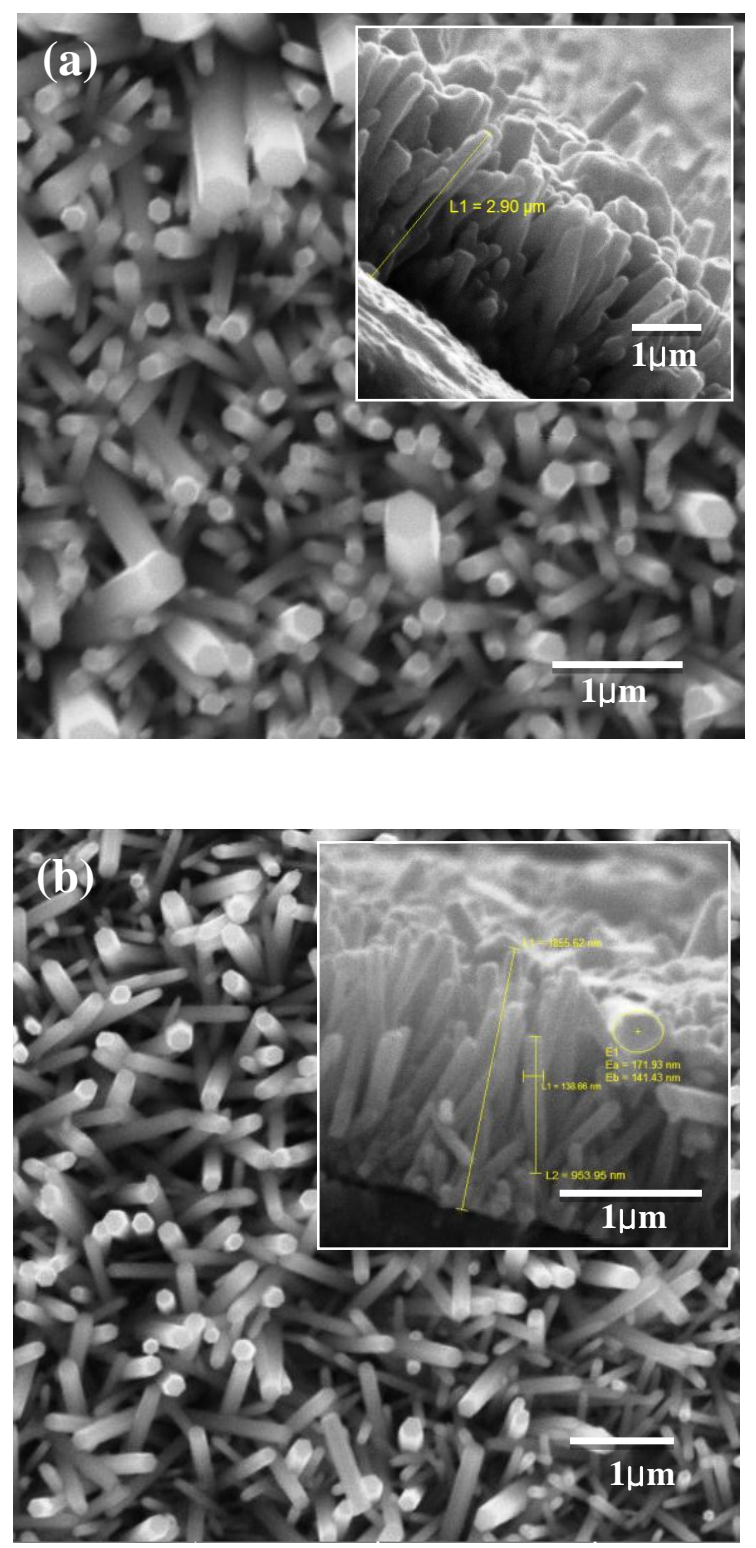

Figure 3: SEM images of ZnO nanowires on FTO (a) 3 times coated (b) 4 times coated, taken at 20.0KV (Inset) Cross-sectional view of $\mathrm{ZnO}$ nanowires

\section{B. XRD Characterization}

The microstructure and crystal structure were examined by using X-Ray Diffraction. Figure 4 exhibit the patterns of zinc oxide nanowires using XDR that were synthesized on FTO substrate with seed layer and with aqueous solution. The range of peak intensity that was measured was $30^{\circ}$ to $70^{\circ}$ at $2 \theta$. The zinc oxide nanowire that was synthesized by the hydrothermal method showed the result with intense diffraction peak at (002) plane, that is detected in between $34^{\circ}$ to $35^{\circ}$. This result shows the pure hexagonal wurtzite structure in c-axis orientation of $\mathrm{ZnO}$ samples possessed.

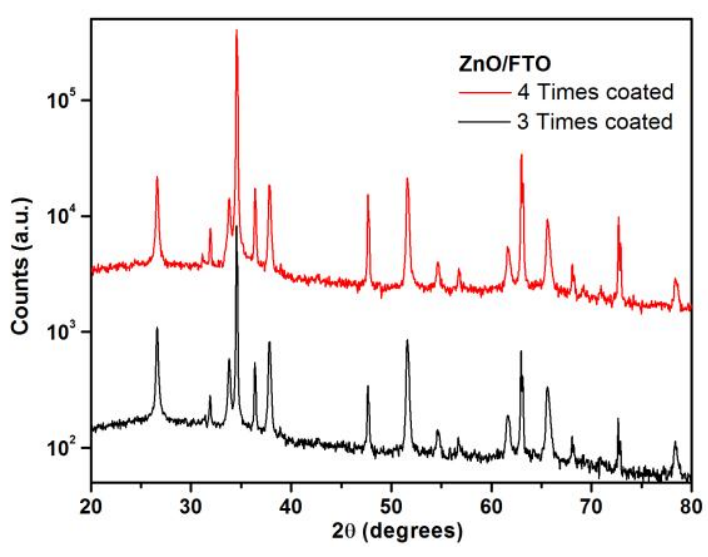

Figure 4: XRD spectra of $\mathrm{ZnO}$ nanowires on FTO.

\section{PL Characterization}

In this characterization we studied the effect of ethanol on luminescence properties of zinc oxide nanowires via photoluminescence spectroscopy. Figure 5 indicates the spectra of PL that grown on substrate. Sample exhibit two clear peaks, which had ultra violet emissions of 350 to 420 $\mathrm{nm}$ and the visible emission at 420 to $630 \mathrm{~nm}$. In the UV range the first emission band was located which caused by the recombination of free exictons through an excitonexciton collision. Second emission band emerge from the deep-level emission. This band exhibits the radiative recombination of photogenerated hole with electron that possessing to the individually ionized oxygen vacancies. Crystal quality of material can be evaluated by using UV luminescence and structural defects can be determined by using visible luminescence.

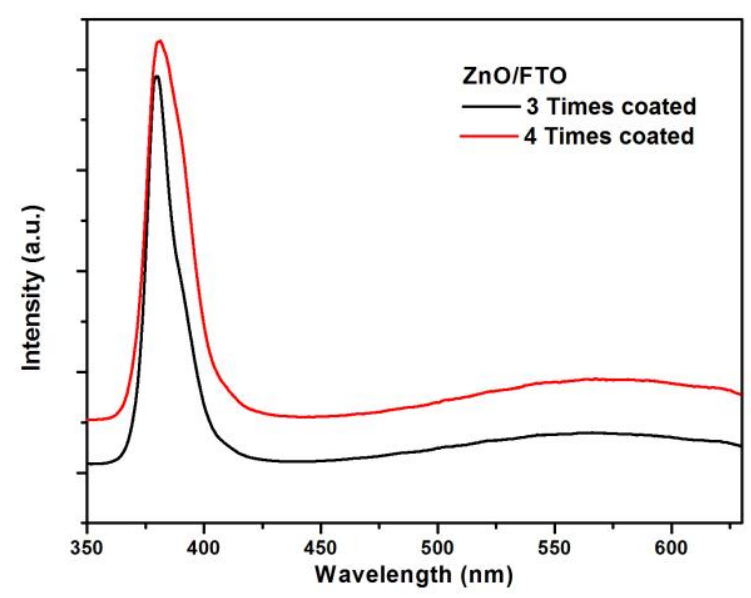

Figure 5: PL spectra of $\mathrm{ZnO}$ nanowires on FTO.

\section{Raman Characterization}

The Raman spectroscopy data of both $\mathrm{ZnO}$ nanowires samples on FTO are shown in figure 6. As evident in figure 4 , the Raman spectra shows a strong peak at $435 \mathrm{~cm}^{-1}$ for 
Proc. of the Sixth International Conference on Advances in Computing, Electronics and Communication - ACEC 2017. Copyright (C) Institute of Research Engineers and Doctors. All rights reserved.

ISBN: 978-1-63248-138-2 doi: 10.15224/ 978-1-63248-138-2-04

the $\mathrm{ZnO}$ nanowires of both samples, which correspond to the E 2 (high) mode of the Raman active mode and it is a characteristic peak for the wurtzite hexagonal phase of $\mathrm{ZnO}$ nanowires, as clear in XRD spectra and SEM images. The strong peak at $435 \mathrm{~cm}^{-1}$ and no other peak in the Raman spectra for $\mathrm{ZnO}$ nanowires is clear proving that our samples have high crystalline quality.

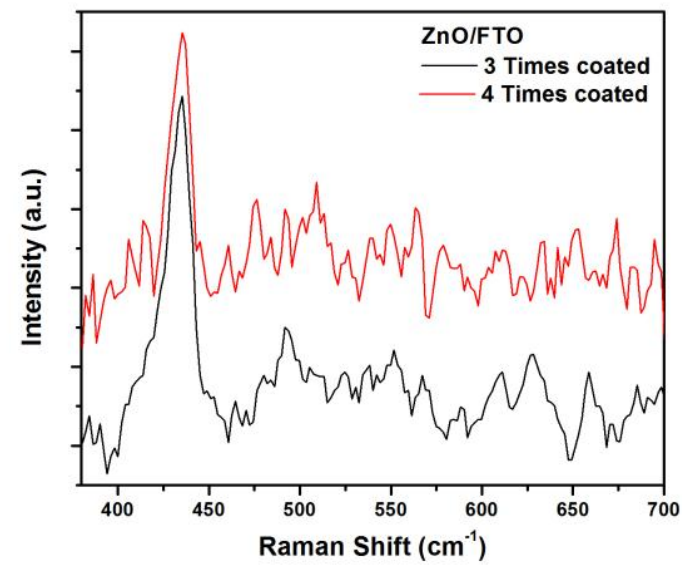

Figure 6: Raman spectra of $\mathrm{ZnO}$ nanowires on FTO.

\section{v. Conclusions}

In this study, zinc oxide nanowires were synthesized by a convenient hydrothermal method and a low cost with highly crystalline structure. The diameter and length of hydrothermal synthesized zinc oxide nanowires is determine by the SEM image of samples. The diameters of zinc oxide nanowires range from 150 to $200 \mathrm{~nm}$ and length range from 1000 to $1500 \mathrm{~nm}$. The XRD patterns showed that all zinc oxide nanowires had extraordinary crystal quality and having high c-axis orientations. The diameter, crystal quality, optical bandgap and grain size of zinc oxide nanowire were influenced by the variety of solvent used in preparation of seed layer. The method elaborate in this study is only to provide a low cost, low temperature and simple fabrication of zinc oxide nanowires with preferred properties. Hydrothermal growth method for zinc oxide nanowires could be helpful in large area of application ranging from resistive switching to light emitting diodes.

\section{References}

[1] Özgür U, Hofstetter D, Morkoç H. ZnO devices and applications: a review of current status and future prospects. Proc IEEE 2010;98:1255-68.

[2] Ryu R, Lee TS, Lubguban JA, White HW, Kim BJ, Park YS, et al Next generation of oxide photonic devices: $\mathrm{ZnO}$ based ultraviolet light emitting diodes. Appl Phys Lett 2006;88:241108.

[3] Kind H, Yan H,Messer B, LawBW, Yang PD. Nanowire ultraviolet photodetectors and optical switches. Adv Mater 2002;14:158-61.

[4] Yang PD, Yan H, Mao S, Russo R, Johnson J, Saykally R, et al. Controlled growth of $\mathrm{ZnO}$ nanowires and their optical properties. Adv Funct Mater 2002;12:323-31.

[5] X. Wang, J. Song, P. Li et al., "Growth of uniformly aligned
$\mathrm{ZnO}$ nanowire heterojunction arrays on $\mathrm{GaN}$, AlN, and Al0.5Ga0.5N substrates," Journal of the American Chemical Society, vol. 127, no. 21, pp. 7920-7923, 2005.

[6] S. J. Young, L. W. Ji, S. J. Chang et al., "Nanoscale mechanical characteristics of vertical $\mathrm{ZnO}$ nanowires grown on ZnO:Ga/glass templates," Nanotechnology, vol. 18, no. 22, Article ID 225603, 2007.

[7] J. J. Wu and S. C. Liu, "Low-temperature growth of well-aligned $\mathrm{ZnO}$ nanorods by chemical vapor deposition," Advanced Materials, vol. 14, no. 3, pp. 215-218, 2002.

[8] B. Xiang, P. Wang, X. Zhang et al., "Rational synthesis of ptype zinc oxide nanowire arrays using simple chemical vapor deposition," Nano Letters, vol. 7, no. 2, pp. 323-328, 2007.

[9] W. I. Park, G. C. Yi, M. Kim, and S. J. Pennycook, “ZnO nanoneedles grown vertically on $\mathrm{Si}$ substrates by non-catalytic vapor-phase epitaxy," Advanced Materials, vol. 14, no. 24, pp. 1841-1843, 2002

[10] YE. Sun, G. M. Fuge, and M.N. R. Ashfold, "Growth of aligned $\mathrm{ZnO}$ nanorod arrays by catalyst-free pulsed laser deposition methods," Chemical Physics Letters, vol. 396, no. 1-3, pp. 2126, 2004.

[11] Huang M, Wu Y, Feick H, Tran N, Weber E, Yang PD. Catalytic growth of zinc oxide nanowires by vapor transport. Adv Mater 2001;13:113-6.

[12] Yang PD, Yan H, Mao S, Russo R, Johnson J, Saykally R, et al. Controlled growth of $\mathrm{ZnO}$ nanowires and their optical properties. Adv Funct Mater 2002;12:323-31.

[13] Cui JB, Gibson UJ. Enhanced nucleation, growth rate and dopant incorporation of $\mathrm{ZnO}$ nanowires. J Phys Chem B 2005;109:22074-7.

[14] J. H. Na, M. Kitamura, M. Arita, and Y. Arakawa, "Hybrid pn junction light-emitting diodes based on sputtered $\mathrm{ZnO}$ and organic semiconductors," Applied Physics Letters, vol. 95, no. 25, Article ID 253303, 2009.

[15] J. Xu, J.Han, Y. Zhang, Y. Sun, and B. Xie, "Studies on alcohol sensing mechanism of $\mathrm{ZnO}$ based gas sensors," Sensors and Actuators, B, vol. 132, no. 1, pp. 334-339, 2008.

[16] S. Chu, G.Wang,W. Zhou et al., "Electrically pumped waveguide lasing from $\mathrm{ZnO}$ nanowires," Nature Nanotechnology, vol. 6, no. 8, pp. 506-510, 2011.

[17] P. Sudhagar, R. S. Kumar, J. H. Jung et al., "Facile synthesis of highly branched jacks-like $\mathrm{ZnO}$ nanorods and their applications in dye-sensitized solar cells," Materials Research Bulletin, vol. 46, no. 9, pp. 1473-1479, 2011.

[18] C. Y. Lu, S. J. Chang, S. P. Chang et al., "Ultraviolet photodetectors with $\mathrm{ZnO}$ nanowires prepared on $\mathrm{ZnO}: \mathrm{Ga} / \mathrm{glass}$ templates," Applied Physics Letters, vol. 89, no. 15, Article ID 153101, 2006.

[19] Yoo, E.J., Shin, I.K., Yoon, T.S., Choi, Y.J. and Kang, C.J., 2014. Resistive switching characteristics of ZnO nanowires. Journal of nanoscience and nanotechnology, 14(12), pp.9459-9464.

[20] S. Cho, S. Kim, J. W. Jang et al., "Large-scale fabrication of sub-20-nm-diameter $\mathrm{ZnO}$ nanorod arrays at room temperature and their photocatalytic activity," Journal of Physical Chemistry C, vol. 113, no. 24, pp. 10452-10458, 2009. 
Proc. of the Sixth International Conference on Advances in Computing, Electronics and Communication - ACEC 2017. Copyright (C) Institute of Research Engineers and Doctors. All rights reserved.

ISBN: 978-1-63248-138-2 doi: 10.15224/ 978-1-63248-138-2-04

About Author (s):

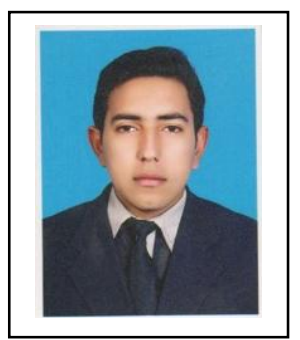

Muhammad Quddamah khokhar received the B.Sc degree in Electrical Engineering from Bahauddin Zakariya University, Multan, Pakistan in 2015. Presently I am doing Master degree in Electrical Engineering at College of Electrical and Mechanical Engineering, National University of Sciences and Technology, Islamabad, Pakistan. My current area of research is zinc oxide nanowires

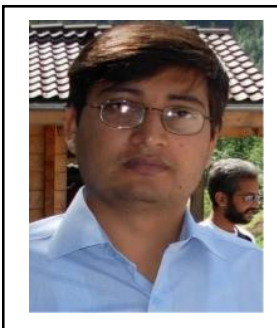

Tanveer Ashraf did his $\mathrm{PhD}$ from institute of semiconductor and solid state physics, Johannes Kepler University Linz Austria, in 2011. Presently he is working as associate professor in National institute of Laser and Optronics Islamabad.

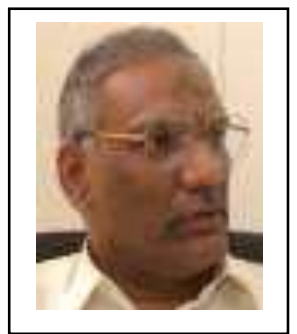

Tahir Zaidi received his Ph.D. degree from Georgia Institute of Technology, School of Electrical and Computer Engineering, United States in 2010 in Compound Semiconductors. Currently, he is Associate Professor with Department of Electrical Engineering,

College of Electrical and Mechanical Engineering,

National University of Sciences and Technology,

Islamabad, Pakistan.

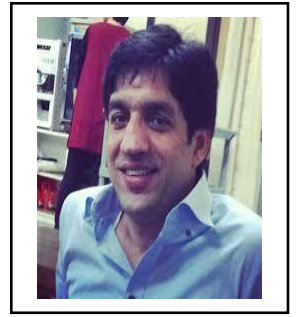

Zahid Ali received his $\mathrm{PhD}$ from Sungkyunkwan University South Korea, in 2012. Currently he is working as associate professor in National institute of Laser and Optronics Islamabad.

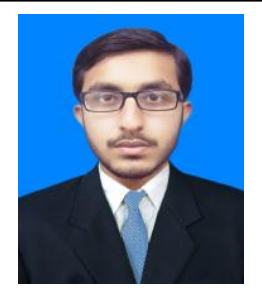

Mansoor Hussain received the B.Sc degree in Electrical Engineering from COMSATS Institute Of Information And Technology, Islamabad, Pakistan in 2015. Presently he is doing Master degree in Electrical Engineering at College of Electrical and Mechanical Engineering, National University of Sciences and Technology, Islamabad, Pakistan. His current area of research is resistive switching. 